\title{
O acesso à educação superior e o fortalecimento da identidade negra
}

Eugenia Portela de Siqueira Marques' (D)

\section{RESUMO}

Este artigo discute a afirmação da identidade negra dos estudantes ingressantes pelo sistema de cotas nos cursos de graduação da Universidade Federal da Grande Dourados. Metodologicamente se optou pela pesquisa bibliográfica, análise documental e entrevistas estruturadas. $\mathrm{O}$ estudo apontou que os estudantes negros podem ressignificar e fortalecer seu pertencimento identitário por meio da participação em grupos de pesquisas e do envolvimento em eventos e ações que promovem debates sobre as implicações de ser negro no Brasil. Os resultados apontaram que, além do acesso à educação superior, outros fatores influenciam a permanência desses estudantes, considerando que a sua diferença negra tensiona a cultura universitária.

PALAVRAS-CHAVE

pertencimento identitário; população negra; preconceito racial.

'Universidade Federal da Grande Dourados, Dourados, MS, Brasil. 


\title{
ACCESS TO HIGHER EDUCATION AND STRENGTHENING OF THE BLACK IDENTITY
}

\begin{abstract}
This article discusses the affirmation of the black identity of students entering the system of quotas in undergraduate courses at Universidade Federal da Grande Dourados. Methodologically, we opted for bibliographic research, documental analysis and structured interviews. The study pointed out that black students can re-signify and strengthen their identity, through participation in research groups and involvement in events and actions that promote debates about the implications of being black in Brazil. The results pointed out that, in addition to access to higher education, other factors influence the permanence of these students, considering that their black difference tensions the university culture.
\end{abstract}

\section{KEYWORDS}

identity belonging; black population; racial preconception.

\section{EL ACCESO A LA EDUCACIÓN SUPERIOR Y EL FORTALECIMIENTO DE LA IDENTIDAD NEGRA}

\section{RESUMEN}

Este artículo discute la afirmación de la identidad negra de los estudiantes ingresantes por el sistema de cuotas en los cursos de graduación de la Universidade Federal da Grande Dourados. Metodológicamente se optó por la investigación bibliográfica, análisis documental y entrevistas estructuradas. El estudio apuntó que los estudiantes negros pueden resignificar y fortalecer su pertenencia identitaria, por medio de la participación en grupos de investigación y del involucramiento en eventos y acciones que promueven debates sobre las implicaciones de ser negro en Brasil. Los resultados apuntaron que además del acceso a la educación superior, otros factores influyen en la permanencia de esos estudiantes, considerando que su diferencia negra genera tensiones a la cultura universitaria.

PALABRAS CLAVE

pertenencia identitária; población negra; prejuicio racial. 


\section{INTRODUÇÃO}

Este artigo discute a afirmação da identidade negra dos estudantes ingressantes pelo sistema de cotas nos cursos de graduação da Universidade Federal da Grande Dourados (UFGD), no contexto da democratização do acesso à educação superior no Brasil, que historicamente foi marcada pela exclusão de jovens oriundos de camadas populares por meio de critérios seletivos de exclusão em que a educação superior não era considerada um bem público, com a finalidade precípua de atender indistintamente a todos os cidadãos em um projeto democrático, solidário e heterogêneo.

A partir da década de 1990, com a implantação de ações afirmativas, gradativamente se observa um novo desenho da política de educação superior, com o acesso de outro perfil de ingressantes, que em sua maioria eram a primeira geração de sua família a ingressar no ensino superior, pois a ausência de políticas de promoção de igualdade racial inviabilizava a entrada de jovens negros na universidade.

As reivindicações dos movimentos sociais, em especial do Movimento Negro, a partir da década de 1990 pressionaram o Estado brasileiro para que implantasse políticas públicas afirmativas, com programas específicos, visando ao acesso de estudantes negros, indígenas e egressos de escolas públicas a esse nível de ensino.

A denominada Lei de Cotas, n. 12.711/2012, sancionada em 29 de agosto de 2012, prevê a reserva de vagas nas instituições federais de ensino superior (IFES) aos estudantes de escolas públicas, de baixa renda, pretos, pardos e indígenas. A atual realidade representa um avanço significativo, tendo em vista que busca garantir a igualdade de direito e a minimização das desigualdades raciais na educação superior.

Transcorridos cinco anos da aprovação dessa lei, alguns resultados de pesquisa apontam para o aumento da população negra nas universidades. A expectativa é de que o número de pretos, pardos e indígenas aumente significativamente nos campi e altere a realidade do "espelho distorcido", ou seja,

apesar dos avanços nos últimos anos, o campus brasileiro continua sendo um espelho que distorce a sociedade. Números analisados e contas feitas, a conclusão a que se chega é uma só: os cursos de graduação hipertrofiam, no campus, as desigualdades existentes. (Ristoff, 2013, p. 11)

Hodiernamente ainda permanecem algumas questões a serem respondidas, em virtude das lacunas deixadas pela referida lei:

- Em que medida a implantação da lei n. 12.711 ampliou o percentual de pretos e pardos nas IFES?

- A adoção do critério exclusivo da autodeclaração da raça contribuirá para a afirmação identitária, e em que medida existe o risco de ocorrerem fraudes?

- As instituições de ensino (IES) manterão critérios próprios e complementares à lei que favoreçam o acesso de minorias etnicorraciais?

- No âmbito da autonomia institucional, quais os critérios adicionais específicos adotados em estados com grande concentração de povos indígenas e/ou quilombolas para garantir a equidade no acesso? 
- Que medidas serão adotadas pelo governo federal e pelas instituições para garantir a permanência material e simbólica dos cotistas?

Cabe ressaltar que esse rol de questões não é exaustivo e, paralelamente, ainda permanece o campo de representações sobre relações etnicorraciais no Brasil, que se caracteriza em um espaço de disputas e também de difícil assimilação na universidade, "ainda alimentada pela ideia do perigo de se estar racializando uma sociedade que nunca teve o fator racial como critério para a diferenciação de sua sociabilidade" (Paiva, 2013, p. 66).

No que tange à autodeclaração de pertencimento étnico-racial para ter direito a cotas, verifica-se que essa medida pode resultar em fortalecimento da identidade negra ou em negação ao seu reconhecimento. Esses aspectos apontam para as diferentes formas de atravessamentos identitários que resultam no acesso e na permanência no espaço universitário, que por sua vez não reflete a composição racial da sociedade brasileira, com mais de $50 \%$ da população declarando-se preta e parda. O censo demográfico de 2010 apontou a grande diferença que existe no acesso a níveis de ensino pela população negra. No grupo de pessoas de 15 a 24 anos que frequentava o nível superior, $31,1 \%$ eram brancos, enquanto apenas $12,8 \%$ eram pretos e $13,4 \%$, pardos.

\section{AS POLÍTICAS AFIRMATIVAS E O ACESSO DA POPULAÇÃO NEGRA À EDUCAÇÃO SUPERIOR NO BRASIL}

A adoção de políticas afirmativas no Brasil para o acesso da população negra ao ensino superior, além de buscar a reparação ou a compensação das desigualdades entre negros e brancos, possibilitou o debate acerca do racismo e da discriminação racial fazendo emergir reflexões sobre o pertencimento étnico-racial. O critério raça possui sentidos diferentes nas políticas afirmativas de alguns países, diferentemente do que acontece no Brasil, que adotou nas políticas de cotas para o acesso à educação superior esse critério.

As políticas afirmativas são, pois, medidas voltadas para a correção das desigualdades e a garantia de direitos, ou seja, visa garantir a grupos excluídos meios e oportunidade de participação em todos os setores da sociedade. Segundo Jaccoud e Beghin (2002,p. 67), as ações afirmativas são políticas que: "Têm por objetivo garantir a oportunidade de acesso dos grupos discriminados, ampliando sua participação em diferentes setores da vida econômica, política, institucional, cultural e social”.

É pertinente ressaltar que as ações afirmativas não se restringem à reserva de vagas por meio do sistema de cotas raciais ou sociais nas universidades, conforme o entendimento mais comum na sociedade. Elas são políticas públicas ou privadas, compulsórias ou não, que têm por objetivo último erradicar da sociedade as práticas discriminatórias dirigidas a determinados grupos sociais, historicamente excluídos e cujo reconhecimento e prestígio social sejam baixos ou mesmo inexistentes. Ao direito à igualdade foi acrescentado o direito à diferença e à diversidade, cuja proteção advém do princípio da equidade. 
As ações afirmativas no Brasil não ficaram restritas apenas à população negra, mas em vários momentos foram adotadas políticas afirmativas em prol de grupos que se encontravam em desvantagem, a exemplo da Lei do Boi, sancionada em julho de 1968 e revogada somente em 1985, que assegurava até $50 \%$ das vagas nos estabelecimentos públicos de ensino agrícola para agricultores ou seus filhos (Gomes, 2002, p. 125).

A adoção de políticas afirmativas voltadas para a população negra fundamenta-se nos diversos dados de pesquisas e estudos sobre as desigualdades abissais entre negros e brancos que permaneceram na sociedade brasileira desde o período pós-escravidão, conforme identificado nas pesquisas de Hasenbalg (1979) e Henriques (2001), entre outros.

A desigualdade na educação não é diferente. A partir do ensino médio, há uma desigualdade acentuada na frequência entre brancos e negros, ou seja, os jovens negros se evadem ou são reprovados no ensino médio e não são inseridos na educação superior na mesma proporção que os brancos, conforme mostra o Gráfico 1.

As políticas afirmativas que se efetivam por meio das cotas raciais representam, por isso, uma estratégia de acesso dessa população que, embora seja a maioria na sociedade, está sub-representada na educação superior.

Analisando os dados, nota-se que ocorreram mudanças significativas, porém sabemos que, considerando o histórico da população negra no Brasil, há um caminho extenso a ser percorrido para se chegar a uma igualdade de fato. A adoção de políticas afirmativas por meio de cotas raciais nas instituições públicas contribuiu,

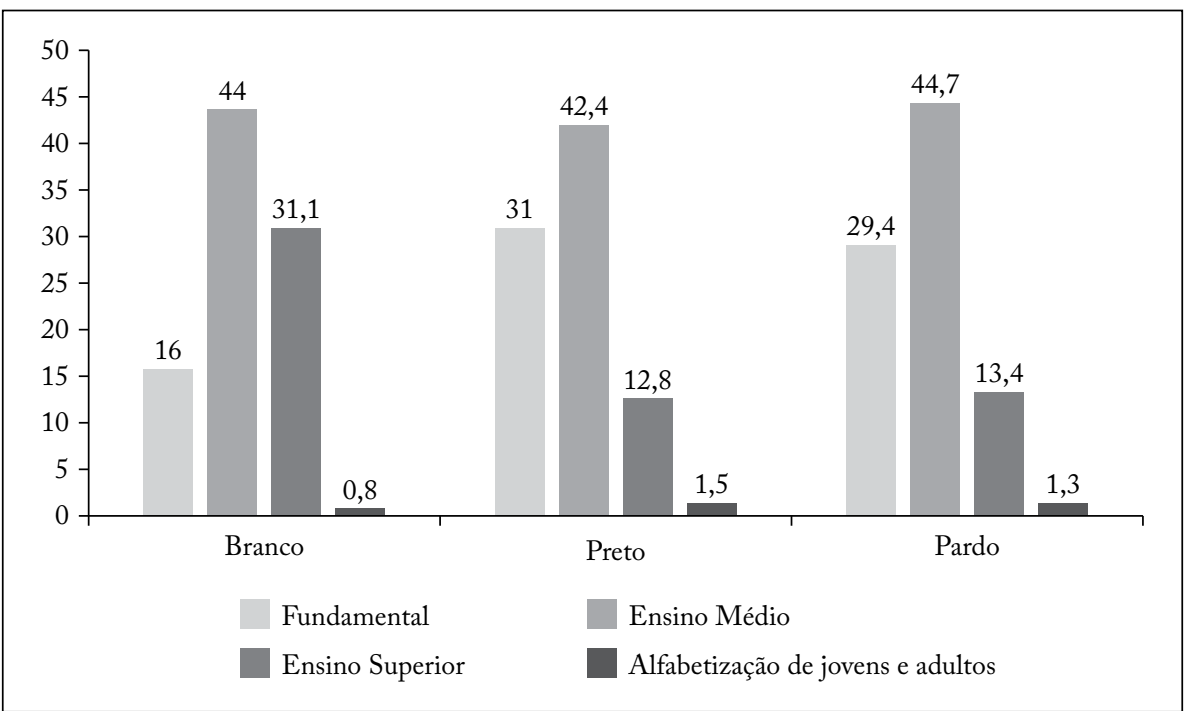

Gráfico 1 - População de 15 a 24 anos que frequentavam escola, por cor ou raça, segundo o nível de ensino (em \%).

No gráfico, ensino superior integra a soma da pós- graduação (especialização, mestrado e doutorado) e ensino fundamental e médio apenas na modalidade regular. Disponível em: <https://sidra.ibge.gov.br/Tabela/2977\#resultado>. Acesso em: 30 out. 2018.

Fonte: IBGE, Censo Demográfico 2010 (Brasil, 2011). 
então, para a presença de maior número de acadêmicos negros na educação superior. De acordo com Daflon, Feres e Campos (2013, p. 41), "as políticas de ação afirmativa, particularmente as de recorte étnico-racial, têm tido um papel fundamental nessa grande mudança, tanto no plano prático como no simbólico". Também é importante ressaltar a importância das reivindicações do Movimento Negro para mudar o cenário das universidades.

Sendo assim, embora existam avanços, há muito que ser feito para se alcançar de fato a igualdade no Brasil, marcado historicamente pela desigualdade racial e social entre brancos e negros, o que demonstra que o racismo ainda está presente em nossa sociedade. De acordo com Paixão et al. (2010, p. 26),

O reconhecimento de que tenha ocorrido queda nas desigualdades em alguns indicadores recentes dos grupos de cor ou raça no Brasil não implica que tal movimento tenha ocorrido com uma intensidade suficiente para se poder dizer que as desigualdades entre brancos, de um lado, e pretos \& pardos, de outro, tenham sido superadas ou possam vir a sê-lo em um curto espaço de tempo.

Há de se concordar com o autor, pois, apesar dos avanços, faz-se necessária a desmitificação da desigualdade em todos os setores da sociedade, trazendo às claras todo o enfretamento que a população negra tem sofrido ao longo da história. Fica visível que somente a adoção de políticas afirmativas universais não é suficiente para amenizar a desigualdade existente ao longo da história da sociedade brasileira. Por isso o recorte de cotas raciais é tão importante na busca por igualdade de oportunidades para a população negra, visto que as políticas de cunho universalistas com capacidade de inserir toda a população negra foram insuficientes em todos os setores, principalmente em relação à educação superior.

Entre as políticas públicas que visam proporcionar o acesso à educação superior, ressaltam-se as políticas posicionadas como focais, que criam vagas especialmente para grupos discriminados, entre os quais: negros, indígenas e estudantes egressos do ensino público.

Historicamente, ainda, sabe-se que determinados grupos étnicos têm dificuldades em ingressar e permanecer na educação superior, onde são largamente sub-representados pretos, pardos e indígenas. Tal se dá por razões históricas, relacionadas ao nascimento e desenvolvimento do Brasil. Para que estes estudantes tenham acesso às universidades, é preciso que se construam políticas públicas específicas. (Vanstreels, 2014, p. 24)

Conforme pontua Vanstreels (2014,p. 24): "Para que estes estudantes tenham acesso às universidades, é preciso que se construam políticas públicas específicas".

Cabe ressaltar que tais políticas foram fruto das reivindicações dos movimentos sociais, em especial do Movimento Negro, que pressionou o governo para inserir na agenda oficial estratégias e políticas focalizadas na população negra. A democratização da educação superior revela que as instituições eram compostas pela classe privilegiada, mas as pressões pela inclusão da população negra na educação superior deram origem ao debate acerca de ações afirmativas. Para a efetivação dessas 
ações, faz-se necessária a intervenção do Estado, uma vez que a ele compete traçar diretrizes gerais. Em contrapartida, há também grupos que tiveram seus direitos negados, para os quais existe a urgência de se amenizar tamanha desigualdade.

Portanto, ações afirmativas são medidas voltadas a atender às particularidades de grupos excluídos, na busca da igualdade de tratamento. $\mathrm{O}$ direito de acesso ao ensino superior para grupos passou a ser garantido com a implementação da lei n.12.711, de 29 de agosto de 2012, ao disciplinar nos artigos $1^{\circ}$ ao $4^{\circ}$, in verbis:

Art. $1^{\circ}$. As instituições federais de educação superior vinculadas ao Ministério da Educação reservarão, em cada concurso seletivo para ingresso nos cursos de graduação, por curso e turno, no mínimo 50\% (cinquenta por cento) de suas vagas para estudantes que tenham cursado integralmente o ensino médio em escolas públicas.

Art. $2^{\circ}$. Vetado.

Art. $3^{\circ}$. Em cada instituição federal de ensino superior, as vagas de que trata o art. $1^{\circ}$ desta lei serão preenchidas, por curso e turno, por autodeclarados pretos, pardos e indígenas e por pessoas com deficiência, nos termos da legislação, em proporção ao total de vagas no mínimo igual à proporção respectiva de pretos, pardos, indígenas e pessoas com deficiência na população da unidade da Federação onde está instalada a instituição, segundo o último censo da Fundação Instituto Brasileiro de Geografia e Estatística - IBGE.

Art. $4^{\circ}$. As instituições federais de ensino técnico de nível médio reservarão, em cada concurso seletivo para ingresso em cada curso, por turno, no mínimo $50 \%$ (cinquenta por cento) de suas vagas para estudantes que cursaram integralmente o ensino fundamental em escolas públicas. (Brasil, 2012, p. 1, grifos da autora)

Cabe ainda ressaltar que a lei, ao estabelecer o critério da autodeclaração para pretos e pardos e não prever a adoção de banca verificadora dessa autodeclaração, deixou para as instituições de ensino buscarem mecanismos para o controle e o acompanhamento de sua aplicação, bem como para a adoção de medidas para coibir possíveis fraudes. Nesse período de implementação da Lei de Cotas, algumas instituições receberam denúncias de fraudes, principalmente nos cursos mais concorridos, entre os quais: medicina, direito e engenharia. A solução foi a implantação de comissões para a verificação da validação da autodeclaração, a fim de coibir farsas, considerando-se que a Lei de Cotas não prevê a banca, mas indica que em qualquer momento, se houver denúncia, o acadêmico poderá ser desligado do curso.

\section{IDENTIDADE NEGRA: ASPECTOS ENTRE A NEGAÇÃO E O RECONHECIMENTO}

Os processos pelos quais o ser humano é acometido ao longo de sua vida estão ligados à construção de sua identidade. Segundo Hall (2006, p. 13), "O sujeito assume identidades diferentes em diferentes momentos, identidades que não são unificadas ao redor de um 'eu' coerente". 
O autor apresenta três concepções de identidade presentes na história da humanidade:

1. sujeito do Iluminismo: o sujeito centrado em seu núcleo interior;

2. sujeito sociológico: sujeito modificado pela relação estabelecida com o outro;

3. sujeito pós-moderno: a identidade do sujeito está em constante transformação.

Nota-se que o termo identidade traz consigo dimensões sociais, pessoais e coletivas, isto é, o indivíduo vai construindo sua identidade de acordo com sua inserção em determinado grupo. Como sinaliza Gomes (2003, p. 41), "A identidade não é algo inato. Ela se refere a um modo de ser no mundo e com os outros. É um fator importante na criação das redes de relações e de referências culturais dos grupos sociais".

Assim, verifica-se que a identidade não é fixa, ou seja, está em constante transformação, como pontua Dayrell (1996, p. 141),

Nessa perspectiva, nenhum indivíduo nasce homem, mas constitui-se e se produz como tal, dentro do projeto de humanidade do seu grupo social, num processo contínuo de passagem da natureza para a cultura, ou seja, cada indivíduo, ao nascer, vai sendo construído e vai-se construindo enquanto ser humano.

Identifica-se o pensamento com o de Hall (2006, p. 13), que diz que a identidade unificada e coerente é uma fantasia. Sendo assim, tanto a construção como o fortalecimento da identidade se dão por meio das relações estabelecidas pelos sujeitos durante a sua vida.

Nesse sentido, trazemos as considerações dos estudos culturais que definem o sujeito como um ser sociável que recebe influências culturais do ambiente em que está inserido. Para Hall (2006, p. 7), "as velhas identidades são desestabilizadas pelo novo que faz surgir novas identidades no contexto contemporâneo”.

A construção da identidade é influenciada, portanto, pelas relações que se dão nos grupos em que os indivíduos estão inseridos. Segundo Gomes (2003, p. 171), "construir a identidade negra positiva em uma sociedade que, historicamente, ensina ao negro, desde muito cedo, que para ser aceito é preciso negar-se a si mesmo, é um desafio enfrentado pelos negros brasileiros".

Toda essa situação leva a reconhecer que a construção e o fortalecimento da identidade são permeados pelas relações dos indivíduos dentro de seu grupo. Para isso, destaca-se que se fazem necessários meios que oportunizem ao sujeito essa construção e essa afirmação. Como afirma Munanga (2012, p. 12):

[...] esta identidade passa, em seu processo de construção, pela cor da pele. $\mathrm{O}$ que significaria que essa identidade tem a ver com a tomada de consciência da diferença biológica entre "Brancos" e "Negros", "Amarelos" e "Negros" enquanto grupos. É importante frisar que a negritude, embora tenha sua origem na cor da pele negra, não é essencialmente de ordem biológica. [...] A negritude 
ou a identidade negra se refere à história comum que o olhar do mundo ocidental "branco" reuniu sob o nome de negros.

Trazemos aqui a história da população negra no Brasil, que é marcada pela colonialidade. Segundo Mignolo (2003, p. 40), "o entendimento da colonialidade do poder pressupõe a diferença colonial como sua condição de possibilidade e como aquilo que legitima a subalternização do conhecimento e a subjugação dos povos". Aqui um destaque para a herança do eurocentrismo presente na América Latina. Quijano (2005, p. 239) pontua:

Aplicada de maneira específica à experiência histórica latino-americana, a perspectiva eurocêntrica de conhecimento opera como um espelho que distorce o que reflete. Quer dizer, a imagem que encontramos nesse espelho não é de todo quimérica, já que possuímos tantos e tão importantes traços históricos europeus em tantos aspectos, materiais e intersubjetivos. Mas, ao mesmo tempo, somos tão profundamente distintos. Daí que quando olhamos nosso espelho eurocêntrico, a imagem que vemos seja necessariamente parcial e distorcida. Aqui a tragédia é que fomos conduzidos, sabendo ou não, querendo ou não, a ver e aceitar aquela imagem como nossa e como pertencente unicamente a nós. Dessa maneira seguimos sendo o que não somos. $\mathrm{E}$ como resultado não podemos nunca identificar nossos verdadeiros problemas, muito menos resolvê-los, a não ser de uma maneira parcial e distorcida.

No Brasil, temos a herança de um passado escravocrata que, mesmo muito tempo passado da abolição, permeia as relações sociais, o que leva o sujeito negro a construir sua identidade em meio a constantes conflitos identitários, em uma sociedade preconceituosa que valoriza, aliás, a cultural europeia. As características físicas do negro, principalmente a cor da pele, o formato do nariz e da boca e a textura dos cabelos são aspectos que levam esses sujeitos a serem vítimas de preconceito e discriminação.

Cabe destacar que, quanto mais próximo das características do branco, o negro tem mais chance de não sofrer preconceito racial. Nogueira (2006, p. 292) sinaliza essa situação ao definir:

O preconceito de raça se exerce em relação à aparência, isto é, quando toma por pretexto para as suas manifestações os traços físicos do indivíduo, a fisionomia, os gestos, o sotaque, diz-se que é de marca; quando basta a suposição de que o indivíduo descende de certo grupo étnico para que sofra as consequências do preconceito, diz-se que é de origem.

Nota-se que no Brasil predomina o preconceito de marca, ou seja, as características fenotípicas ditam as regras para que o negro seja mais ou menos discriminado. Conforme ressalta Gomes (2002, p. 41),

$\mathrm{Na}$ instituição escolar, assim como na sociedade, nós comunicamo-nos por meio do corpo. Um corpo que é construído biologicamente e simbolicamente 
na cultura e na história. A antropologia mostra-nos que as singularidades culturais são dadas não somente pelas dimensões invisíveis das relações humanas. São dadas, também, pelas posturas, pelas predisposições, pelos humores e pela manipulação de diferentes partes do corpo.

Sobre esse aspecto, em sua pesquisa Corpo e cabelo como icones de construção da beleza e da identidade negra nos salóes étnicos de Belo Horizonte, a autora revela o que as entrevistadas destacam

[...] várias depoentes, ao se reportarem ao corpo, relembraram momentos significativos da sua história de vida, dando um destaque especial à trajetória escolar. Para essas pessoas, na sua maioria mulheres negras jovens e adultas, na faixa dos 20 aos 60 anos, a experiência com o corpo negro e o cabelo crespo não se reduz ao espaço da família, das amizades, da militância ou dos relacionamentos afetivos. (Gomes, 2002, p. 41)

Verifica-se, pois, que o processo identitário do negro perpassa ao longo da história do Brasil por estigmas que sempre inferiorizam a sua cultura e exalta os valores eurocêntricos. Nesse aspecto, Munanga (2004,p.110) descreve: "o processo de construção dessa identidade brasileira, na cabeça da elite pensante e política, deveria obedecer a uma ideologia hegemônica baseada no ideal do branqueamento".

Os valores eurocêntricos predominam na sociedade brasileira, e tudo aquilo que não se enquadra neles sofre discriminação e preconceito. Munanga (2012,p. 6) sinaliza que: "além da identidade nacional brasileira, que reúne a todas e todos, estamos atravessados/as por outras identidades de classe, sexo, religião, etnias, gênero, idade, raça, etc., cuja expressão depende do contexto relacional".

Como a identidade é construída pelas inter-relações do sujeito, a sua discussão deve estar presente na sociedade.

A identidade é uma realidade sempre presente em todas as sociedades humanas. Qualquer grupo humano, através do seu sistema axiológico, sempre selecionou alguns aspectos pertinentes de sua cultura para definir-se em contraposição ao alheio. (Munanga, 1994, p. 177-178)

E como construir ou afirmar a identidade negra em uma sociedade em que se encontram arraigados valores eurocêntricos, em que tudo que se relacionada com o negro é inferiorizado? Precisa-se compreender que a construção dessa identidade nos leva a entender as relações sociais que fazem parte da vida dos sujeitos, sejam brancos ou negros, como pontua o autor.

O mito de democracia racial, baseado na dupla mestiçagem biológica e cultural entre as três raças originárias, tem uma penetração muito profunda na sociedade brasileira: exalta a ideia de convivência harmoniosa entre os indivíduos de todas as camadas sociais e grupos étnicos, permitindo às elites dominantes dissimular as desigualdades e impedindo os membros das comunidades não brancas de terem consciência dos mecanismos de exclusão da qual são vítimas na sociedade. (Munanga, 2004, p. 89) 
Ressalta-se aqui que, no Brasil, o mito da democracia racial que prega a igualdade entre todos não é bem assim, uma vez que exalta somente a cultura europeia e inferioza as demais, inclusive a cultura negra. Nota-se que a ideologia do branqueamento influenciou a construção da identidade do povo brasileiro, negando a existência da herança de outros povos, principalmente do africano, na composição dessa identidade. Quando mencionado, esse povo aparece de forma folclorizada ou estereotipada.

Diante dessa realidade, ressaltam-se os desafios que o negro enfrenta para ressifgnificar ou afirmar sua identidade. Segundo Santos e Silva (2005, p. 40), "o processo de fortalecimento da identidade racial brasileira é uma possibilidade de enfrentamento da discriminação racial". Tais enfrentamentos fazem parte do cotidiano do negro em todos os aspectos: sociais, culturais e econômicos.

Entendemos, pois, que é preciso levar em consideração questões sociais, políticas, étnicas, individuais e coletivas que influenciam na construção ou no fortalecimento da identidade de cada pessoa.

A definição de identidade coletiva, de acordo com Munanga (2012, p. 9):

É uma categoria de definição de um grupo. Esta definição pode ser feita pelo próprio grupo através de alguns atributos selecionados no seu complexo cultural (língua, religião, arte, sistemas políticos, economia, visão do mundo), de sua história, de seus traços psicológicos letivos, etc., entendidos como mais significativos do que outros e que o diferenciam de demais grupos ou comunidades, religiões, nações, etnias, etc. O que "nós", antropólogos, chamamos de sinais diacríticos.

Dentro da categoria autodefinição, o autor declara que o primeiro fator constitutivo dessa identidade é a história. Mas, se "a história é fator principal, como construir essa identidade se mal a conhecemos, uma vez que ela foi contada do ponto de vista do 'outro', de maneira depreciativa e negativa"(Munanga, 2012, p. 9).

É, portanto, fundamental para a população negra reencontrar o fio condutor da verdadeira história do negro que o liga à África, sem distorções nem falsificações, para, assim, ir apropriando-se de sua história. Munanga (2012, p. 10) assinala:

[...] no processo de construção da identidade coletiva negra, é preciso resgatar sua história e autenticidade, desconstruindo a memória de uma história negativa que se encontra na historiografia colonial ainda presente em "nosso" imaginário coletivo e reconstruindo uma verdadeira história positiva capaz de resgatar sua plena humanidade e autoestima destruída pela ideologia racista presente na historiografia colonial.

Verifica-se a importância do estudo da história da população negra de maneira clara, sem distorções, em que se oportunize ao sujeito o autoafirmar-se em seu pertencimento racial nesse contexto de discriminação em que a autonegação ainda é frequente.

Como sujeitos sociais, é no âmbito da cultura e da história que definimos as identidades sociais (todas elas, e não apenas a identidade racial, mas também as 
identidades de gênero, sexuais, de nacionalidade, de classe, etc.). Essas múltiplas e distintas identidades constituem os sujeitos, na medida em que estes são interpelados a partir de diferentes situações, instituições ou agrupamentos sociais. Reconhecer-se numa delas supõe, portanto, responder afirmativamente a uma interpelação e estabelecer um sentido de pertencimento a um grupo social de referência. (Gomes, 2003, p. 171)

Outro fator que contribui para a construção da identidade negra, segundo a autora, é "a cultura (religiões, artes, medicinas, tecnologias, ciências, educação, visões do mundo, etc.)". Quando é tratada no Brasil a história dos povos que o construíram, conforme Munanga (2012, p. 1):

[...] os aportes culturais africanos fazem parte do cotidiano de todos os brasileiros: culinário, artes musicais, visuais, religiões populares, breve, estão presentes na maneira de ser brasileiro e brasileira. De fato, a cultura brasileira no plural e sua identidade nacional foram modeladas pelos aportes da população negra. Estas contribuições culturais precisam ser resgatadas positivamente, desconstruindo imagens negativas que fizeram delas e substituindo-as pelas novas imagens, positivamente reconstruídas.

E sobre o fator psicológico que contribui para a construção da identidade, ainda destaca Munanga (2012, p. 11):

Mas, neste caso, devemos perguntar-nos se existe um temperamento do negro diferente do temperamento do branco que podemos considerar como característica de sua identidade. Tal diferença se for comprovada, deveria ser explicada a partir notadamente do condicionamento histórico do negro dentro da estrutura sociopolítica assimétrica, e também de acordo com suas estruturas sociais comunitárias, e não com bases nas diferenças biológicas, como pensaram os racialistas e racistas ocidentais.

A crença de que a população branca é superior à população negra é muito presente na nossa sociedade, o que faz com que se menospreze a capacidade intelectual do negro em todos os setores, não sendo diferente quando se trata da universidade. Faz-se necessário, portanto, que, para além do acesso, a universidade desenvolva, por meio das pró-reitorias de graduação e de assistência estudantil, ações que contribuam para a permanência e o fortalecimento da identidade desses grupos nesse espaço em que a maioria é branca. As políticas afirmativas que têm contribuído para o acesso da população negra à universidade possibilitam a mudança do perfil dos acadêmicos em vários cursos em que a hegemonia branca prevalece.

\section{A AFIRMAÇÃO DA IDENTIDADE COM O ACESSO À EDUCAÇÃO SUPERIOR}

Existem basicamente três métodos de identificação racial, que podem ser aplicados com variantes. Nesse sentido, Osório (2003, p. 7-8) define: 
O primeiro é a autoatribuição de pertença, no qual o próprio sujeito da classificação escolhe o grupo do qual se considera membro. O segundo é a heteroatribuição de pertença, no qual outra pessoa define o grupo do sujeito. $\mathrm{O}$ terceiro método é a identificação de grandes grupos populacionais dos quais provieram os ascendentes próximos por meio de técnicas biológicas, como a análise do DNA. Não há como garantir congruência entre as classificações dos sujeitos obtidas mediante a aplicação desses métodos. Todavia, é razoável esperar convergência quando os sujeitos da classificação se apresentarem de forma próxima ao estereótipo de um grupo, e o contrário se forem indivíduos na fronteira entre dois grupos. Nada impede que mais de um método de identificação seja empregado para a atribuição de pertença. No sistema classificatório do IBGE, são empregados simultaneamente os métodos da autoatribuição e da heteroatribuição de pertença.

As pesquisas do Instituto Brasileiro de Geografia e Estatística (IBGE) mostram exclusivamente a autoatribuição, ou seja, esse mesmo critério foi utilizado para a autodeclaração dos ingressantes por cotas raciais, uma vez que um dos aspectos positivos da Lei de Cotas é possibilitar que o indivíduo se identifique ao se autodeclarar pertencente a determinado grupo.

No período de 2000 a 2010, o percentual de negros cresceu, indo de 44,7\%, no censo de 2000, para 50,9\% em 2010. Em contrapartida, enquanto mais da metade da população $(53,7 \%)$ se autodeclarava branca na pesquisa feita dez anos antes, em 2010 esse percentual caiu para 47,3\%. De acordo com Jefferson Mariano, analista socioeconômico do IBGE, essa inversão faz parte de uma mudança cultural que vem sendo observada desde o censo de 1991. Assim: "Muitos que se autodeclaravam brancos agora se dizem pardos, e muitos que se classificavam como pardos agora se dizem pretos. Isso se deve a um processo de valorização da raça negra e ao aumento da autoestima dessa população" (Mariano, 2012).

A afirmação da identidade negra está diretamente ligada às redes de relações com o outro, ou seja, as relações mantidas pelo sujeito influenciarão o fortalecimento de sua identidade, seja positiva ou negativamente, considerando-se que a identidade não é inata.

Para atingir os objetivos da pesquisa, foi utilizado questionário on-line e entrevistas presenciais. O questionário foi enviado aos acadêmicos ingressantes pelo sistema de cotas por meio de $e$-mails disponibilizados pelos coordenadores dos cursos de graduação da UFGD. Um total 180 ingressantes responderam ao questionário, em um universo de 900 matriculados. Identificaram-se alguns fatores no período de acompanhamento da pesquisa, entre os quais se elencam:

- problemas nos endereços de e-mails cadastrados na matrícula;

- o acadêmico não quis participar da pesquisa;

- a negação de ter ingressado pelas cotas raciais, mesmo tendo se autodeclarado;

- não possuía as características fenotípicas e, consequentemente, não teria direito ao acesso pelas cotas, tendo em vista que naquele período a UFGD não possuía a Comissão Verificadora de Autodeclaração Étnico-racial. 
Foram entrevistados seis acadêmicos, que responderam em tempo hábil, demonstrando interesse em participar da entrevista. Estavam matriculados nos cursos de educação física, nutrição, medicina, pedagogia, relações internacionais e sistema de informação e tinham idade entre 20 e 35 anos. As entrevistas foram agendadas e realizadas no campus, no horário indicado pelos acadêmicos.

No que se refere ao questionamento do fortalecimento da identidade com o acesso à educação superior, não foram identificadas respostas discrepantes se comparadas com as do questionário aplicado aos demais acadêmicos, ou seja, corroboravam os depoimentos dos entrevistados, pois para alguns o acesso à educação superior fortaleceu a identidade negra e para outros não.

A seguir são apresentados trechos das entrevistas dos ingressantes ${ }^{1}$ pelas cotas nos cursos de graduação presencial da UFGD. Quando questionado sobre a afirmação da identidade com acesso à universidade, Andrey afirma:

A afirmação de minha identidade foi crescendo a cada dia, pois me deparei com professores que me deram a oportunidade de participar do NEAB e de um grupo de estudos, o que me abriu a mente em relação a minha raça. Também me encontrei nas disciplinas que trabalham a relação étnico-racial, e não posso me esquecer de que participei da PIVIC e da PIBIC, o que, acredito, me auxiliou nessa afirmação. Confesso que me sentia confuso. A universidade foi um ponto de encontro pessoal, onde pude ingressar em um ambiente tão plural que abalou minhas concepcôes a respeito do mundo como um todo. Sou pardo, filho de negro com caucasiana, e me orgulho muito de minha história e de minha família. A participação nos eventos do NEAB me possibilitou o empoderamento e o conhecimento necessário para aceitar meu lugar real na sociedade: um brasileiro com os mesmos direitos de todos os outros, e não me sujeitar, abaixar a cabeça, recebendo como normais as piadinhas ignorantes e grosseiras. (Andrey, 2016, grifos da autora)

O depoimento de Andrey possui muitos significados e certamente demonstra que o acesso à educação superior, ao conhecimento e à participação nos grupos de estudos propiciou o seu fortalecimento identitário. Além das políticas para o acesso, a trajetória desse acadêmico na universidade foi marcada por situações que contribuíram também para a sua permanência.

A situação de Andrey é diferente da de alguns sujeitos participantes da pesquisa, que não perceberam as contribuições para o fortalecimento identitário. Apesar disso, é inegável que, apesar dessa negação, eles passarão por um processo de ressignificação identitária e, ao final do período, suas identidades não serão as mesmas, como se pode verificar:

Não vi mudança muito grande na questão da identitária com acesso à educação superior. O que tenho já trouxe comigo e não vi nenhuma ação que fizesse

1 Os sujeitos da pesquisa foram identificados por meio de nomes fictícios, a fim de se garantir o anonimato. (Andrey: curso de educação física; Talita: curso de medicina; Pedro Gustavo: sistema de informação; Miguel: curso de relações públicas; Maria: curso de nutrição; Eva: curso de pedagogia). 
fortalecer a minha identidade. O que tem estado fortalecido é o meu desejo de concluir o curso e desempenhar a profissão almejada. (Talita, 2016)

Não sei responder, pois não noto essa contribuição. (Pedro Gustavo, 2016)

Em relação ao processo identitário, antes de entrar na universidade já tinha minha afirmação identitária. (Miguel, 2016)

A universidade não interferiu, pois já me declarava negra. (Maria, 2016)

Não interfere, sou o que sou. (Eva, 2016)

Nota-se que os acadêmicos chegam à universidade com as marcas culturais e sociais decorrentes de como foram ordenados no mundo. Como afirma Dayrell (1996, p. 141),

Nessa perspectiva, nenhum indivíduo nasce homem, mas constitui-se e se produz como tal, dentro do projeto de humanidade do seu grupo social, num processo contínuo de passagem da natureza para a cultura, ou seja, cada indivíduo, ao nascer, vai sendo construído e vai-se construindo enquanto ser humano.

Por essa ótica, o acesso à educação superior possibilitou aos sujeitos ingressantes uma mudança de perspectiva por meio de outras lógicas, diferentes da lógica imposta pela "colonialidade do ser", que enfoca a subalternização e a desumanização dos sujeitos colonizados. O valor humano e as faculdades cognitivas dessas pessoas são desacreditados pela sua cor e raízes ancestrais. A colonialidade do ser, para Mignolo (2003, p. 668), trata da experiência vivida na colonização e de seus impactos na linguagem, que requer a compreensão sobre os efeitos da colonialidade na experiência da vida, e não somente na mente dos colonizados.

Quando Andrey (2016) afirma: "Confesso que me sentia confuso. A universidade foi um ponto de encontro pessoal, onde pude ingressar em um ambiente tão plural que abalou minhas concepções a respeito do mundo como um todo", ele revela os efeitos da colonialidade, que nega aos sujeitos negros a sua humanidade por meio de uma violência epistêmica construída em torno do conceito de raça e os têm como "não europeus", historicamente desumanizados e inferiorizados. Também Hall (1997, p. 22-23) afirma que "é quase impossível para o cidadão comum ter uma imagem precisa do passado histórico sem tê-lo tematizado no interior de uma 'cultura herdada', que inclui panoramas e costumes de época".

As experiências vividas pelos acadêmicos em um novo espaço cultural podem contribuir para que os diferentes grupos sociais, particularmente os negros subalternizados, redescubram o valor positivo de sua cultura e das experiências específicas, a fim de ressignificá-las. Azibeiro (2003, p. 93) sinaliza que "as diferenças culturais não são entendidas como dados ou evidências, que se manifestam naturalmente como antagonismos, mas como construções culturais".

Outra acadêmica afirma que a participação nas atividades do Núcleo de Estudos Afro-brasileiros (NEAB) também contribuiu para o seu fortalecimento identitário. 
Sim, com o contato com os eventos do NEAB passei a ter orgulho da minha cor, dos meus traços e do meu cabelo; deixei velhos preconceitos para trás e me sinto capaz de inspirar outras pessoas a lutarem por seus sonhos. (Eva, 2016) afirma:

O depoimento vai ao encontro dos trabalhos de Gomes (2002, p. 50), que

O estudo sobre o corpo e o cabelo, como ícones da identidade negra presentes nos processos educativos escolares e não escolares, poderá apontar-nos outros caminhos além da denúncia da reprodução de preconceitos e estereótipos. A manipulação do cabelo do negro e da negra, nessa perspectiva, pode ser vista como continuidade de elementos culturais africanos ressignificados no Brasil.

Observa-se que a participação dos acadêmicos em eventos que discutem a temática ligada à população negra pode fortalecer sua identidade, como também pontua Gomes (2003) em sua pesquisa Corpo e cabelo. No contexto da universidade, em que a hegemonia branca prevalece, torna-se evidente que o estereótipo do negro é ponto de identificação que remete à construção ou ao fortalecimento da identidade negra. Como afirma Hall (1996, p. 70), "As identidades culturais são pontos de identificação, os pontos instáveis de identificação ou sutura, feitos no interior dos discursos da cultura e da história”. Isso mostra que identidade cultural são as particularidades que o sujeito ou grupo possui e que o inclui em uma cultura específica.

Diferentes elementos têm sido utilizados pela população negra para a marcação identitária, e o cabelo tem sido um desses elementos que indicam o "pertencimento", a escolha de uma estética que rompe e que se contrapõe às imposições culturais relacionadas ao cabelo "bonito", "bom", "liso", impostas pela cultura eurocêntrica, de ética e estética ditas superiores.

Em relação ao questionamento: "Você se autodeclara cotista em qualquer ambiente (na universidade e fora dela)?”, verificam-se as seguintes respostas:

Eu declaro que sou cotista; não tenho problema com essa situação. Pelo contrário, ao me declarar, abro oportunidade para aqueles que sentem vergonha ou receio de fazer o mesmo que fiz, já que é um direito nosso. (Andrey, 2016)

Eu me declaro cotista em qualquer ambiente. Eu não me vejo diminuída por causa das cotas; é questão de equidade. Nem todos têm as mesmas condições de entrar na universidade por motivos que aconteceram no passado e que, infelizmente, refletem suas consequências ainda hoje. (Talita, 2016)

Sim, eu me declaro porque me sinto pardo e, se sou, me declaro sem problema algum. (Pedro Gustavo, 2016)

Se alguma pessoa vier me perguntar se sou cotista, eu declaro que sim, pois não enxergo isso como vergonha e não tenho nenhum tipo de medo de falar que sou cotista. (Miguel)

Eu me declaro, mas não sei justificar. (Maria, 2016)

Não, ninguém precisa saber. (Eva, 2016) 
As falas mostram que para esses acadêmicos o acesso pelas cotas raciais é um direito. Tanto na sociedade quanto no espaço acadêmico, os debates sobre a constitucionalidade das cotas foram acirrados, mas com a implantação da lei n. 12.711/2012 as manifestações contrárias não impedem o gozo dos direitos dos cotistas.

Gomes contribui com a reflexão, no tocante à fala da acadêmica Eva, ao afirmar:

Construir uma identidade negra positiva em uma sociedade que, historicamente, ensina aos negros, desde muito cedo, que para ser aceito é preciso negar-se a si mesmo é um desafio enfrentado pelos negros e pelas negras brasileiros(as). (Gomes, 2005, p. 43)

A universidade poderia propor um debate institucional sobre a importância das políticas afirmativas, e até mesmo um diálogo ou seminário envolvendo a comunidade de acadêmicos, a fim de minimizar a falta de conhecimento dessa política. Além disso, importante também o fato de que, se o aluno cotista não participar de coletivos ou de ações do NEAB, ele ingressa no ensino superior pelas cotas e finaliza o curso na instituição sem ter a consciência ou o conhecimento sobre a importância histórica desses mecanismos que promoveram a democratização do acesso.

De acordo com Munanga (2012, p. 10), é preciso resgatar a história da população negra de forma positiva, em que a sua autoestima possa ocupar o lugar da memória negativa presente ao longo de sua história.

A universidade precisa, por isso, estar atenta a essa situação e promover ações que valorizem a diversidade e oportunize a seus acadêmicos assumirem esse direito em qualquer ambiente. Como pontua o ex-coordenador do NEAB, Márcio Macedula Aguiar, também entrevistado:

[...] é preciso criar uma universidade que não seja eurocêntrica e branca; isso ainda tem que ser feito porque o que acontece, às vezes, é que o indivíduo entra pelas cotas e, ao invés de sair da universidade se reafirmando negro, sai como branco. Isso tem a ver com essa dificuldade que nós ainda temos de reformular a própria concepção de universidade. (Aguiar, 2016)

A invisibilidade da população negra na universidade ocorre em todos os setores, conforme salientado anteriormente. Para verificar a percepção dos acadêmicos, foi indagado: "Você identifica a presença de outras pessoas negras na universidade?".

A maioria dos entrevistados e as respostas do questionário on-line demostraram que na UFGD a presença do negro é pequena, conforme se pode verificar na fala da participante da pesquisa: "Tenho contato com alguns alunos, porém professores só tive uma, além de alguns funcionários da limpeza" (Maria, 2016, grifos da autora).

A questão da desigualdade educacional e de renda ainda afeta diretamente a população negra, o que dificulta a sua mobilidade dentro do mercado de trabalho. Essa percepção da estudante Maria ratifica o que os dados estatísticos mostram constantemente: os negros são maioria nos setores econômicos que têm as piores condições laborais (agricultura, construção civil, vigilância e trabalhos domésticos) e também nas posições mais precárias ou de menor remuneração. 
Essa realidade presente na sociedade reflete na universidade, pois são poucos os negros na docência, em pró-reitorias ou como servidores administrativos. Nesse contexto, evidencia-se mais um desafio para os acadêmicos negros fortalecerem sua identidade, se em suas vivências o referencial de posições em destaque permanece sendo majoritariamente branco.

Percebem-se as dificuldades encontradas pelo acadêmico negro no espaço universitário, porém, diante de tantos obstáculos, há aqueles que se utilizam dessa situação para afirmar positivamente sua identidade, uma vez que ela se dá na interação com o outro. Isso fica evidente quando o acadêmico Andrey relata que "a cada dia consegue afirmar sua identidade e quer contribuir para a transformação da sociedade", e também quando afirma em seu comentário sobre se declarar cotista:

Eu declaro, pois, o acesso por meio das cotas à universidade realmente demonstra que suas portas estão abertas para todas as raças. $\mathrm{O}$ sistema precisa, todavia, melhorar e dar mais suporte ao estudante, não se limitando somente ao ingresso, mas também à promoção e ao debate sobre a inclusão racial. Hoje, a presença dos negros, embora em números bem tímidos, merece total destaque. (Andrey, 2016)

O depoimento retrata que gradativamente, ainda que em número inferior, os negros vão colorindo o espaço acadêmico, mas que as instituições de ensino devem buscar mecanismos para, além do acesso, promoverem a sua permanência ali, conforme alerta Heringer (2013, p. 86), quando diz que se trata de um desafio posto para as IES públicas considerarem como "parte de suas tarefas e responsabilidade a necessidade de lidar com a emergência desse novo perfil de estudante universitário, que chega com diferentes necessidades e requer atenção especial por parte das instituições".

Um fator importante destacado na pesquisa, o qual também contribui para a afirmação da identidade, é a participação do cotista nos eventos do NEAB/UFGD. Isso ficou evidente pelas respostas dadas à questão: "Você participa dos eventos promovidos pelo Núcleo de Estudos Afro-Brasileiros da Universidade Federal da Grande Dourados?"

Eu procuro participar dos eventos promovidos pelo NEAB, importantes para a minha vida acadêmica e para a sociedade como um todo. Assim eu posso colaborar e de certa forma retribuir o que eu ganhei. Estou conseguindo firmar minha identidade cada dia mais, descobrir o meu pertencimento e o sentimento de pertencer a um grupo de pessoas que sofrem na sociedade por discriminação, por preconceito. (Andrey, 2016)

Outros acadêmicos que responderam ao questionário on-line assinalaram:

Discussões sobre etnia, miscigenação e classe social me fizeram ter orgulho de meus ancestrais, principalmente por ser contra a estatística, pois sou pobre e parda e estou em uma universidade federal, elitizada, sim, mas faço parte do começo da mudança. 
Os debates realizados no NEAB e os estudos do tema me auxiliaram a questionar e a fortalecer minha identidade.

Tenho me agarrado a minha negritude após minha participação nos eventos do NEAB.

Também pontua o entrevistado Andrey (2016),

Quero continuar a conhecer cada vez mais a questão das relações étnico-raciais no nosso país e no mundo. Vou ver como poderei retribuir o que recebi e contribuir com a nossa sociedade para transformá-la mudando esse pensamento predominante de que a cor branca é superior à cor preta.

Em relação à discriminação sofrida pelo negro na universidade, identificam-se, nas falas dos acadêmicos entrevistados, situações em que a discriminação e o preconceito racial se materializam direta ou indiretamente, como se pode verificar nas respostas dos participantes quando questionados: "Você foi discriminado na universidade devido ao seu pertencimento racial?”. Vejamos os depoimentos:

Fui discriminado mais de uma vez. A mais marcante ocasião foi um dia em que fui de bicicleta para a universidade. Chegando ao bloco, o segurança ordenou que eu descesse da bicicleta porque era perigoso, isso de forma bem grosseira. Eu ia assistir a uma aula no sábado de manhã e só havia alunos da minha turma no local, então eu não via perigo ali. Acho que ele agiu assim de certa forma por questões de preconceito, pois na hora percebi que ele era um segurança bem alto e branco. [...] Foi um ato de discriminação. Imagine você, numa universidade federal, uma pessoa negra chega de bicicleta; imagine o olhar daquele segurança para mim. (Andrey, 2016)

Nos depoimentos do questionário on-line, evidenciam-se as seguintes respostas:

Já ouvi o seguinte comentário: "Você é espertinho, tem jeito de branco aqui na faculdade".

E se não fosse a Dilma dar as cotas, onde você estaria?

Já agradeceu à Dilma hoje?

Cada coisa que se vê! Cotas para quem não sabe nada.

Sim, já me chamaram de cabelo duro.

Sim, fui chamado de cabelo pixaim.

As falas dos acadêmicos retratam, além do preconceito, a defesa da meritocracia e a certeza de que a universidade não é espaço para os negros ingressantes pelas cotas, além de ignorarem o significado das políticas afirmativas iniciadas no governo de Fernando Henrique Cardoso. Reproduzem a ideia de que são políticas partidárias que ignoram o sentido de constitucionalidade. Conforme ilustra Gomes (2003, p. 3), 
[...] a identidade negra é entendida como um processo construído historicamente em uma sociedade que padece de um racismo ambíguo e do mito da democracia racial. Como qualquer processo identitário, ela se constrói no contato com o outro, no contraste com o outro, na negociação, na troca, no conflito e no diálogo.

Percebe-se, pois, que a discriminação se manifesta de diversas formas, como pontua Marques (2010, p. 217): “[...] a discriminação racial pode se manifestar de diferentes modos e graus, desde os apelidos e piadas que tendem a inferiorizar o outro, até a ofensa física”.

\section{CONSIDERAÇÕES FINAIS}

As políticas afirmativas em curso na educação superior possibilitam o acesso da população negra à universidade, porém ainda apresentando inúmeros desafios para a permanência e o êxito acadêmico. Entre esses tantos aspectos, encontra-se a possibilidade de os jovens negros fortalecerem seu pertencimento étnico-racial em um espaço historicamente homogêneo, no qual a diversidade cultural e racial antes não se fazia presente.

$\mathrm{O}$ estudo apontou que os acadêmicos envolvidos em eventos e ações que discutiam a temática da população negra e que participavam de grupos de estudos de iniciação científica tiveram mais condições de fortalecimento identitário. As disciplinas de direitos humanos e educação das relações étnico-raciais também contribuíram com aqueles que tiveram a oportunidade de cursá-las, bem como as ações de extensão e pesquisa realizadas pelo NEAB/UFGD.

Muitos dos participantes, no entanto, não se encontravam envolvidos com essas ações. Por isso a importância de a universidade estar atenta ao fato de propiciar situações que valorizem a diversidade étnico-racial cada vez mais presente no campus.

Apesar das dificuldades enfrentadas pela população negra, as políticas afirmativas têm contribuído para mudar o espaço universitário, com o toque da diversidade. Embora os obstáculos enfrentados pelos sujeitos estudados estejam além das dificuldades comuns a todos os acadêmicos, muitos deles se utilizam dessas situações para fortalecer sua identidade com o contato com a história da população negra. Para Munanga (2012), o resgate da história é fator essencial para aumentar a autoestima dos sujeitos pertencentes a esse grupo.

Também é importante salientar que o fortalecimento da identidade negra se dá em meio a muitas tensões, principalmente em uma sociedade em que, segundo Gomes (2005), o negro é ensinado a negar a si mesmo. Ou seja, a imposição do etnocentrismo produz um ideal de homem com características predominantemente brancas.

Com a inserção desses novos sujeitos e suas diferenças, o grande desafio posto à universidade é garantir um espaço de interlocução e de visibilidade a lógicas outras, um espaço em que aconteçam as tensões, as negociações e a ressignificação, que a lógica antes naturalizada seja subvertida e transformada. 


\section{REFERÊNCIAS}

Azıbeiro, N. E. Educação intercultural e complexidade: desafios emergentes a partir das relações em comunidades populares. In: FLEURI, R. M. (Org.). Educação intercultural: mediações necessárias. Rio de Janeiro: DP\&A, 2003.

Brasil. Lei n. 5.465, de 3 de julho de 1968. Dispõe sobre o preenchimento de vagas nos estabelecimentos de ensino agrícola. Diário Oficial da União, Brasília, DF, 4 jul. 1968. Seção 1, p. 5.537. Disponível em: <http://www2.camara.leg.br/legin/fed/lei/1960-1969/ lei-5465-3-julho-1968-358564-publicacaooriginal-1-pl.html>. Acesso em: 29 out. 2018.

. Censo demográfico 2010. Rio de Janeiro: IBGE, 2011. Disponível em: <www. ibge.gov.br/home/presidência>. Acesso: 1 mar. 2016.

. Instituto Nacional de Estudos e Pesquisas Educacionais Anísio Teixeira - INEP. Censo da educação superior: 2011 - resumo técnico. Brasília, DF; INEP. Disponível em: <http://download.inep.gov.br/download/superior/censo/2011/resumo_ tecnico_censo_educacao_superior_2011.pdf>. Acesso em: 29 out. 2018.

Lei n. 12.711, de 29 de agosto de 2012. Dispõe sobre o ingresso nas universidades federais e nas instituições federais de ensino técnico de nível médio e dá outras providências. Diário Oficial da União, Brasília, DF, 30 ago. 2012. Disponível em: $<$ http://www.planalto.gov.br/ccivil_03/_ato2011-2014/2012/lei/112711.htm>. Acesso em: 18 nov. 2017.

Aguiar, M.M. Márcio Macedula Aguiar: depoimento [abr. 2016]. Entrevista concedida a: Maria Aparecida Pereira dos Santos Ribeiro, 12 abr. 2016.

Daflon, V. T.; Feres Júnior, J.; Campos, L. A. Ações afirmativas raciais no ensino superior público brasileiro: um panorama analítico. Cadernos de Pesquisa, São Paulo: Fundação Carlos Chagas; Campinas: Autores Associados, v. 43, n. 148, p. 302-327, jan./abr. 2013. http://dx.doi.org/10.1590/S0100-15742013000100015

DAYrell, J. A escola como espaço sociocultural. In: Múltiplos olhares sobre a educação e cultura. Belo Horizonte: UFMG, 1996. p. 136-161.

Gomes, N. L. Trajetórias escolares, corpo negro e cabelo crespo: reprodução de estereótipos ou ressignificação cultural? Revista Brasileira de Educação, Rio de Janeiro: ANPEd; Campinas: Autores Associados, n. 21, p. 40-51, 2002. http://dx.doi. org/10.1590/S1413-24782002000300004

. Educação, identidade negra e formação de professores/as: um olhar sobre o corpo negro e o cabelo crespo. Revista Educação e Pesquisa, São Paulo: USP, v. 29, n. 1, p. 167-182, jan./jun. 2003. https://doi.org/10.1590/S1517-97022003000100012

. Alguns termos e conceitos presentes no debate sobre relações raciais no Brasil: uma breve discussão. In: Secretaria de Educação Continuada, Alfabetização e Diversidade. Educação antirracista: caminhos abertos pela lei federal n. 10.639/03. Brasília, DF: MEC; Secretaria de Educação Continuada e Alfabetização e Diversidade, 2005. p. 39-62.

Hall, S. Identidade cultural e diáspora. Revista do Patrimônio Histórico e Artístico Nacional, Rio de Janeiro: IPHAN, n. 24, p. 69-75, 1996. 
. A centralidade da cultura: notas sobre as revoluções culturais do nosso tempo. Revista Educaşão e Realidade, Porto Alegre: UFRGS, v. 22, n. 2, p. 15-46, jul./dez. 1997. . A identidade cultural na pós-modernidade. Tradução de Tomaz Tadeu da Silva e Guacira Lopes Louro. Rio de Janeiro: DP\&A, 2006.

Hasenbalg, C. A. Discriminação e desigualdades raciais no Brasil. Rio de Janeiro: Graal, 1979.

Heringer, R. O próximo passo: as políticas de permanência na universidade pública. In: PAiva, A. R. Ação afirmativa em questão: Brasil, Estados Unidos, África do Sul e França. Rio de Janeiro: Pallas, 2013.

Henriques, R. Desigualdade racial no Brasil: evolução das condições de vida na década de 90. Texto para discussão n. 807. Rio de Janeiro: IPEA, jul. 2001. Disponível em: <http:// www.ipea.gov.br/portal/index.php?option $=$ com_content\&view $=$ article\&id=4061 > . Acesso em: 29 out. 2018.

Jaccoud, L.; Beghin, N. Desigualdades raciais no Brasil: um balanço da intervenção governamental. Brasília, DF: IPEA, 2002.

Marques, E. P. S. O Programa Universidade para Todos e a inserção de negros na educação superior: a experiencia de duas instituições de educação superior de Mato Grosso do Sul - 2005-2008. 2010. Tese (Doutorado em Educação) — Universidade Federal de São Carlos, São Carlos, 2010.

Mariano, J. Cresce o número de pessoas que se autodeclaram negras, segundo o IBGE. 2012. Disponível em: <http://www.palmares.gov.br/?p=21203>. Acesso em: 12 dez. 2017.

Mignolo, W. Histórias globais/projetos locais. Colonialidade, saberes subalternos e pensamento liminar. Belo Horizonte: UFMG, 2003.

Munanga, K. Identidade, cidadania e democracia: algumas reflexões sobre os discursos antirracistas no Brasil. In: SPINK, M.J.P. (Org.).A cidadania em construção: uma reflexão transdisciplinar. São Paulo: Cortez, 1994. p. 177-187.

. Estratégias e poéticas de combate à discriminação racial. São Paulo: EDUSP; Estação Ciência, 2004.

. Negritude e identidade negra ou afrodescendente: um racismo ao avesso? Revista da ABPN, Goiânia: ABPN, v. 4, n. 8, p. 6-14, jul./out. 2012.

Nogueira, O. O porvo brasileiro. A formação e o sentido do Brasil. São Paulo: Companhia das Letras, 2006.

Osório, R. G. O sistema classificatório de "cor ou raça" do IBGE. Brasília, DF: IPEA, 2003. Disponível em: <http://www.acaoeducativa.org.br/fdh/wp-content/uploads/2012/10/ quesito-cor-IBGE.pdf >. Acesso em: 25 nov. 2017.

Paiva, A. R. Ação afirmativa: Brasil, Estados Unidos, África do Sul e França. Rio de Janeiro: Pallas, 2013.

Paixão, M.; Rosseto, I.; Montovanele, F.; Carvano, L. M. Introdução. In: ;__________ (Orgs.). Relatório anual das desigualdades raciais no Brasil: 2009-2010. Rio de Janeiro: Editora Garamond, 2010. p. 26. Disponível em: <https:// www.geledes.org.br/wp-content/uploads/2014/05/Relat\%C3\%B3rio_2009-2010.pdf>. Acesso em: 15 dez. 2017. 
Quijano, A. Colonialidade do poder, eurocentrismo e América Latina. In: Lander. E. (Org.). A colonialidade do saber: eurocentrismo e ciências sociais. Perspectivas latino-americanas. Buenos Aires: CLACSO, 2005. p. 227-278. (Colección Sur Sur). Disponível em: <http://bibliotecavirtual.clacso.org.ar/ar/libros/lander/pt/Quijano.rtf〉. Acesso em: 20 abr. 2017.

Ristoff, D.Perfil socioeconômico do estudante de graduação: uma análise de dois ciclos completos do ENANDE (2004-2009). Cadernos do GEA, Rio de Janeiro: FLACSO,v. 2, n. 4,p.1-36, jul./dez. 2013. Disponível em: <http://www.flacso.org.br/gea/documentos/ Cadernos_GEAA_N4.pdf $>$.Acesso em: 21 out. 2017.

Santos, G.; Silva, M. P. Racismo no Brasil: percepções das discriminações e do preconceito no século XXI. São Paulo: Fundação Perseu Abramo, 2005.

Vanstreels, C. A democratização e expansão da educação superior no país 2003-2014. Brasilia, DF: MEC,2014. Disponível em: <http://portal.mec.gov.br/docman/dezembro2014-pdf/16762-balanco-social-sesu-2003-2014>. Acesso em: 1 nov. 2017.

\section{SOBRE A AUTORA}

Eugenia Portela de Siqueira Marques é pós-doutora em educação pela Universidade Federal da Grande Dourados (UFGD). Professora da Universidade Federal da Grande Dourados (UFGD).

E-mail: eumar13@terra.com.br

Recebido em 31 de janeiro de 2018

Aprovado em 14 de agosto de 2018 